\title{
Participação de Cientistas e Tecnólogos Brasileiros na "International Conference on Science and Technology of Synthetic Metals - ICSM"
}

Entre os dias 12 e 18 de julho foi realizada na bela cidade de Montpellier no sul da França mais uma edição da Conferência Internacional bianual denominada "Internacional Conference on Science and Technology of Synthetic Metals - ICSM", que tem por tema principal estudos sobre metais sintéticos, nas áreas de física, química e engenharia de materiais. A ICMS vem sendo realizada desde o início da década de 80 , quando do surgimento dos polímeros condutores. Entre os materiais sintéticos que apresentam elevadas condutividades elétricas, e por isso denominados de metais sintéticos, além dos polímeros condutores orgânicos, pertencentes à família dos polímeros de estrutura conjugada, se destacam também os fulerenos e os sais de Bechgaards.

Os materiais poliméricos são matérias-primas em muitos setores da indústria moderna, movimentando bilhões e bilhões de dólares anuais em todo o mundo. Isto se deve principalmente à sua versatilidade em substituir, com vantagens, outros tipos de materiais, sintéticos ou naturais, em diferentes modalidades que servem ao conforto e às necessidades do mundo contemporâneo. Podemos destacar desde a indústria aeroespacial à de embalagens, passando pela de isoladores de alta tensão, de móveis e da construção civil, entre outras. Entretanto, devido às suas propriedades dielétricas os polímeros nunca foram visto como materiais ativos na indústria eletrônica e/ou fotônica. Com a descoberta da variação de condutividade elétrica, por transporte eletrônico, em polímeros conjugados dopados quimicamente, esses materiais hoje começam a disputar também espaço na indústria eletrônica e optoeletrônica. Com os avanços da pesquisa consegue-se variar, de maneira controlada e reversível, a condutividade elétrica de filmes poliméricos em até 15 ordens de magnitude. Portanto, os polímeros, originalmente isolantes elétricos, se tornam condutores e podem ser obtidos com qualquer valor de condutividade dentro da ampla faixa dos semicondutores. Os materiais semicondutores apresentam, do ponto de vista tecnológico, inúmeras propriedades não-convencionais relacionadas a efeitos não-lineares, derivando daí muitas aplicações tecnológicas. Entre essas propriedades destacam-se a retificação em curvas de corrente elétrica versus tensão elétrica, fotocondução, fotoluminescência e eletroluminescência, etc. Esses efeitos são ingredientes, hoje observados nos polímeros eletrônicos, que apontam a novas tecnologias e aplicações. Essas novas propriedades aos materiais plásticos ocorrem, portanto, devido ao controle na síntese e fabricação de filmes de espessuras controladas, ao controle, preciso e reversível, da variação de sua condutividade elétrica, e aos estudos relacionados à geração de portadores elétricos. Outras propriedades, como a emissão de luz, estão associadas a mecanismos de recombinação dos portadores gerados por efeito de dopagem da estrutura do material.

Essa área de investigação completa 20 anos, e sua importância, e vigor, ficaram evidenciadas não só pelo grande número de trabalhos apresentados nessa edição do ICSM, mas sobretudo pela qualidade observada nas pesquisas e pela efervescência nas discussões entre os pesquisadores. Houve a participação de aproximadamente 1100 pesquisadores com cerca de 40 países representados. O Brasil se fez representar por mais de 20 pesquisadores, apresentando 72 trabalhos, sendo três orais. Foram representadas cerca de 25 instituições brasileiras de pesquisa, entre laboratórios de Universidades e de Institutos de pesquisa. Depois do Japão e dos EUA, o 
Brasil foi o país fora da Europa com maior número de participantes, e não fosse pela dificuldade de custo devido à distância, a participação de estudantes brasileiros seria bem maior. Até o final da década de 80 a participação brasileira nessa reunião era relativamente discreta, o que mostra que as pesquisas relacionadas a polímeros condutivos e semicondutivos vêm crescendo consideravelmente em nosso país.

Além do bom número de participantes, os trabalhos

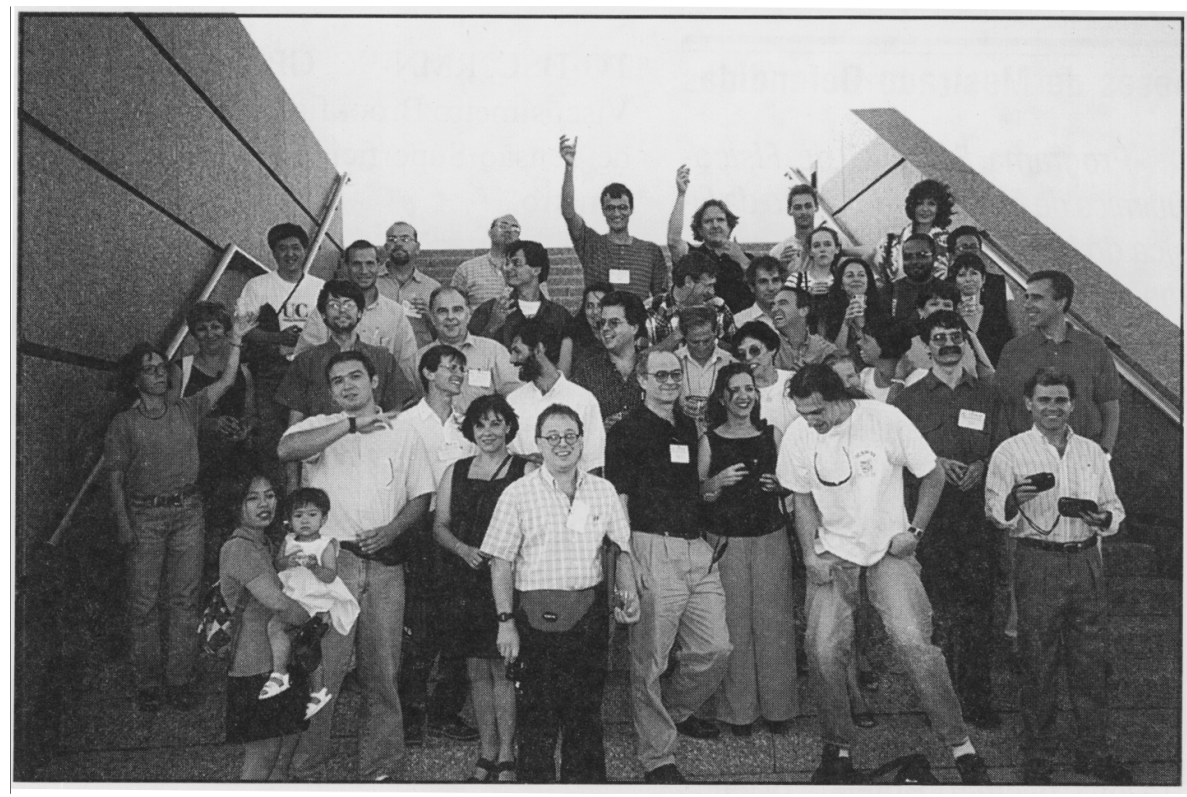
brasileiros foram bem aceitos, pois dentre as 70 apresentações orais três foram escolhidas entre os nossos trabalhos. A Conferência também proporcionou aos brasileiros estabelecer novos contatos visando futuras colaborações, além de dar continuidade e consolidar colaborações já existentes. Através dos trabalhos apresentados pelos brasileiros pôde-se observar que existem colaborações com importantes Centros nos exterior como, por exemplo, com a Universidade da Pensilvânia (EUA) através do prof. A. G. MacDiarmid, com a Universidade de Wroclaw (Polônia) através do prof. J. Sworakowski, e com a Universidade da Califórnia de Santa Barbara.

A Conferência começou dia 12 de julho, dia da final da Copa do Mundo de Futebol. Como não poderia deixar de ocorrer, houve muitos comentários sobre o resultado do jogo Brasil x França. O Chairman da Conferência, prof. Patrick Bernier, gentilmente convidou todos os brasileiros participantes à uma comemoração junto aos organizadores do evento. Essa agradável confraternização aconteceu na tarde do dia 14 de julho registrada pela foto acima. O prof. Bernier

agradeceu a participação do Brasil (também no futebol), e disse ter ficado impressionado com a qualidade das pesquisas que vêm sendo realizadas na área pelos nossos Centros de Pesquisa.

Os brasileiros apresentaram trabalhos em várias sub-áreas que iam desde a síntese de polímeros, da fabricação de filmes ultrafinos de estruturas organizadas, até à confecção de dispositivos eletrônicos e sua caracterização, passando por estudos teóricos e experimentais dos mecanismos de condução eletrônica nesses materiais. No número 1, ano VIII (página 38) dessa revista foi publicado um artigo intitulado Transistor por efeito de campo e fotocondutor de poli(o-metoxianilina) o qual dá uma ótima idéia da aplicação de polímeros semicondutivos como elemento ativo em um dispositivo eletrônico. Outras aplicações potenciais apresentadas por pesquisadores brasileiros na Conferência foram de diodos, células fotovoltáicas, e dispositivos eletroluminescentes.

A próxima "Internacional Conference on Science and Technology of Synthetic Metals - ICSM", deverá ser realizada na Áustria no ano 2.000.

Notícia elaborada pelo Prof. Dr. Roberto Mendonça Faria, Depto. de Física e Ciência dos Materiais, Instituto de Física de São Carlos/ USP, e-mail: faria@ifsc.sc.usp.br 